\title{
COMBINED GEOMETRIC AND THERMAL ANALYSIS FROM UAV PLATFORMS FOR ARCHAEOLOGICAL HERITAGE DOCUMENTATION
}

\author{
R. Brumana ${ }^{(1)}$, D. Oreni ${ }^{(1)}$, L. Van Hecke ${ }^{(2)}$, L. Barazzetti ${ }^{(1)}$, M. Previtali ${ }^{(1)}$, F. Roncoroni $^{(3)}$, R. Valente ${ }^{(1)}$ \\ (1) Politecnico di Milano, Department of Architecture, Built Environment and Construction Engineering \\ Via Ponzio 31, 20133 Milano, Italy \\ (raffaella.brumana, daniela.oreni, luigi.barazzetti)@ polimi.it \\ mattia.previtali@mail.polimi.it ; valenteric@alice.it \\ ${ }^{(2)}$ Raymond Lemaire International Centre for Conservation, Katholieke Universiteit Leuven \\ Kasteelpark Arenberg 1 - 3001 Heverlee, Belgium \\ lissa.vanhecke@student.kuleuven.be \\ (3) Politecnico di Milano, Polo Territoriale di Lecco, Via Marco D'Oggiono 18/A, Lecco, Italy \\ fabio.roncoroni@polimi.it
}

KEY WORDS: Conservation, Image orientation, Laser scanning, Maintenance, Thermal images, UAV

\begin{abstract}
:
The aim of this work is to study the value and potential of UAV technology as an instrument for documenting and analyzing a heritage site on both the detailed scale and the wider territorial scale. In particular, this paper will focus on the application of an UAV platform on the archeological site of Isola Comacina (Comacina Island), in the Lago di Como (Lake Como, Lombardy, Northern Italy). The work considers the advantages of different metric scales and the use of both RGB and thermal imagery, along with other terrestrial data (total station measurements and laser scans), in order to arrive at a working heritage information model. In particular, the archaeological remains on Isola Comacina have been intensively studied before by standard techniques but unfortunately no wider context is provided. A part of the research is the investigation of new methodologies offered by accurate geometric reconstructions combined with thermal imagery acquired by means of UAV platforms, e.g. the support of this type of imagery to discover rock formations partially buried.
\end{abstract}
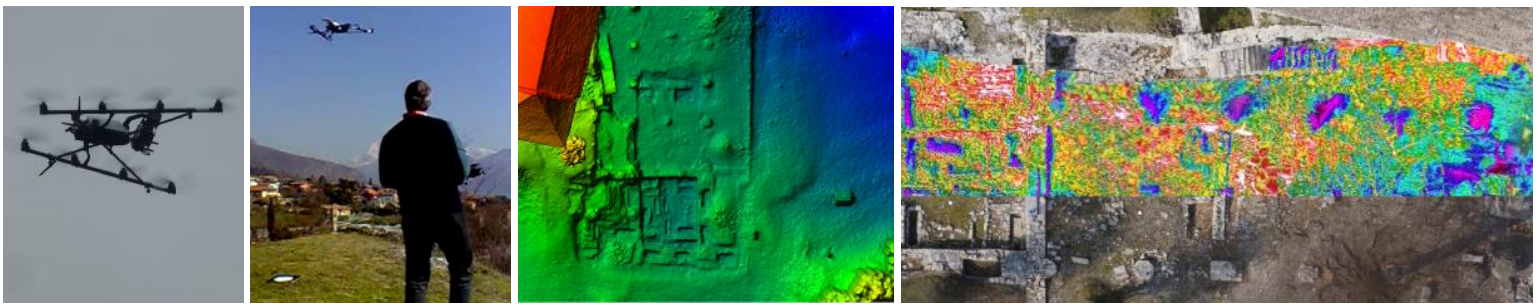

Figure 1. UAV system (Asctec Falcon 8), DEM extracted from digital images, RGB and thermal orthophotos.

\section{INTRODUCTION}

Unmanned Aerial Vehicles (UAVs) have been introduced successfully in different projects in the archaeological field and in the heritage sector. They can be used in high risk situations without endangering the position of the researchers. Moreover, they can reach places that are inaccessible for men or that cannot be reached by manned systems. They are more cost-effective since they do not require a person aboard, leaving no physiological and less economic limitations to the research.

UAVs are also able to present real-time capability and fast date acquisition (Eisenbeiss, 2009), which is becoming more and more important in the current heritage sector. Their considerable small size, weight and operating system are a great advantage for conservation projects in case of transport, steering, processing of data and economic considerations. In the archaeological and heritage sector their application is mainly focused on inspection, surveillance, mapping and 3D modeling, delivering data that can also be applied in other fields such as agriculture, environmental surveying, traffic monitoring, the real estate sector, and 3D reconstruction (Remondino et al., 2011).

Nowadays, the metric documentation of archaeological areas is becoming more and more important. Particular attention is paid to the creation of three-dimensional models or more advanced BIM systems in order to obtain a comprehensive management structure and perform further analysis (e.g. the derivation of two-dimensional drawings and plans, vertical sections, etc., queries or the remote exploration of archaeological sites). For these reasons, the geometric survey is gradually passing from traditional methods, mainly based on direct surveying, to new acquisition techniques allowing integration of multiple data sources. In particular, Terrestrial Laser Scanning (TLS) and Close-range Photogrammetry, along with Unmanned Aerial Vehicle (UAV) images are becoming more important for the rapid and accurate documentation of archaeological area and the availability of new processing algorithms. 
In recent years the application of a UAV in documentation, observation and discovery of heritage sites has shown considerable results, opening up the field for not only aerial photography, but also laser scanning technology (Jaakkola et al., 2010; Glennie et al., 2013), thermal and ultraviolet imagery. Nowadays the generation of RGB orthophotos, DEMs and 3D models is mainly used for the inspection of sites (Brumana et al., 2011; Rinaudo et al., 2012; Seitz and Altenbach, 2011) or the documentation of archaeological excavations (Sauerbier and Eissenbeis, 2010; Eisenbeiss and Sauerbier, 2011).

The scope of this research is to study the value and potential of a UAV as an instrument for documenting and analyzing a heritage site on both the detailed scale and the more wider territorial scale by using both RGB and thermal images. In particular, this paper will focus on the application of an UAV platform (Falcon 8) on Isola Comacina in the Lago di Como (Italy). Here, the archaeological remains were intensively studied (under the influence of the Soprintendenza per i Beni Archeologici - Italian local authorities for heritage) but unfortunately no wider context is provided. The areas were studied individually without a connection between the different sites, their history, location and structural characteristics (Fig. 2).

This research, still in its start-up phase, considers the advantage of different scales and the possibilities of both RGB and thermal imagery to arrive at a working heritage information model. The work is positioned in an international collaboration and trainee program with origins in the ARCHDOC organization of the Raymond Lemaire International Centre for Conservation (Catholic University of Leuven, Belgium) bringing together international specialists from Politecnico di Milan, Tecnalia, English Heritage etc., in the training of young professionals.

In this paper, a brief state of the art of UAVs is provided, followed by a short overview of the history and features of the Isola Comacina sites and the scope of the survey. In the following part, the applied surveying techniques, data processing and the preliminary results are discussed.

\section{THE ARCHAEOLOGICAL SITE}

Isola Comacina is an island located in the Lago di Como (Lombardy, Italy). It had a pole position in the religious, politic and economic history of the region with remains dating back to the Roman and early Christian times into the Middle Ages when it was a fortified small city on Lake Como. It is assumed that in the 12th century destruction struck the island and though the island lost its dominant position, later remains indicate it was never totally deserted (Gianoncelli, 1973).

Isola Comacina takes an important position in the arthistorical history of the area and of Italy, being claimed to be the birthplace of the 'arte Comacina', influencing the Lombard and Romanesque art and building style of the 12th century. Especially interesting for such a small island is the position of an impressive amount of religious architecture, elaborate frescos and stuccos. In the 20th century the island came into the hands of the Belgian king, who passed it back to the Italian authorities and the Brera Art Academy that planned to make the island a resort for artists (D'Amia, 2005). Remnants of that time period are the three restored 'Belgian' artist houses on the island by the hand of architect Pietro Lingeri (Canziani and Della Torre, 2010).

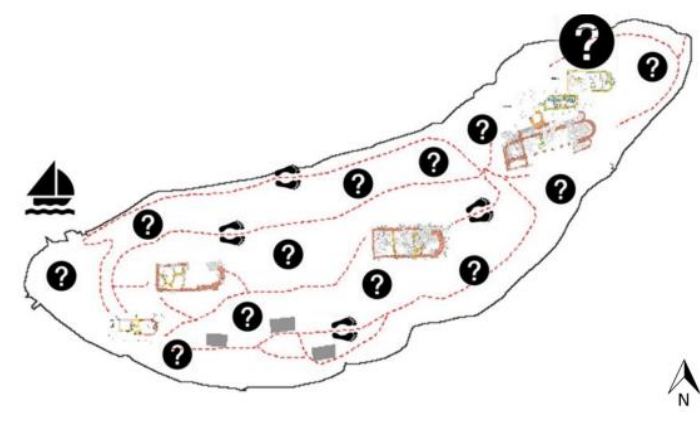

Fig. 2. Simplified plan of Isola Comacina with an indication of the most important structures. The "broken chain concept" is also illustrated: this research made a step towards their connection.

Today the island is a location for tourists with both historical and natural or environmental interests. The archaeological sites on the island are mainly religious remains; the complex of St. Faustino and St. Giovita that was part of a Benedictine monastery, the church of St. Pietro in Castello, the church of St. Maria con Portico, the remains of the basilica of St. Eufemia (Fig.s 2 and 3) with a beautiful arcade and a baptistery close to the contemporary church of St. Giovanni, which covers remains of earlier (Roman and Early Medieval) structures. The original church of St. Giovanni was destroyed in the $12^{\text {th }}$ century and a new church was built in the $17^{\text {th }}$ century. Restoration works were carried out in the late $20^{\text {th }}$ century and the year 2008 and the church was consecrated and opened again for services.

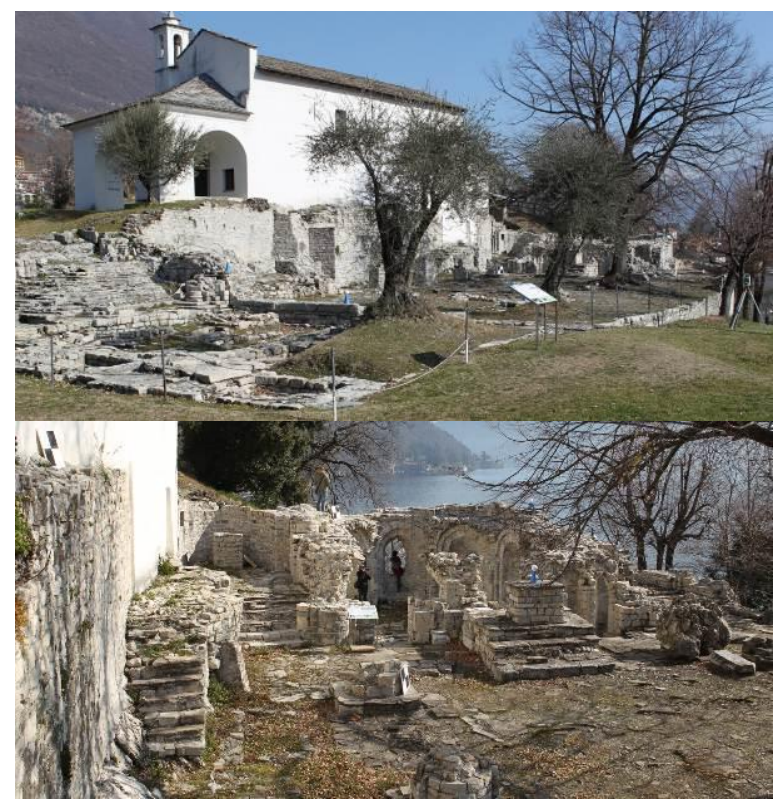

Fig. 3. The church of St. Giovanni with the archaeological remains of the basilica of St. Eufemia in close proximity.

During the survey the interest was focused on the archaeological remains of St. Pietro in Castello, the basilica of St. Eufemia (next to the church of St. Giovanni) and a small hilltop to the north of the church of St. Giovanni. The potentiality of the application of the UAV (with the collection of both RGB imagery and thermal imagery) was to research the importance of different metric scales and the 
execution of an integrated approach combining several survey and documentation techniques and the processing of their data (images, laser scans, total station measurements). Through the use of a UAV and aerial imagery it was possible to focus on different scales: from a small detail on one site to the wider territorial scale and interconnection between the elements on an individual site or between the different sites on the island.

\section{DATA ACQUISITION AND PROCESSING}

\subsection{Terrestrial survey}

The geometrical survey started with the creation of a geodetic network made up of five stations around the church of St. Eufemia. This allowed the creation of a stable reference system where all data (images and laser scans) were registered.

The instrument is a robotic total station Leica TS30 (distance precision $\pm 0.6 \mathrm{~mm}$ and angular precision $\pm 0.15 \mathrm{mgon}$ ) and the adopted scheme is shown in Fig. 4. Several targets were also directly measured in this phase in order to avoid repositioning errors and obtain more precise results. These targets include retro-reflective tapes mounted on stable objects (e.g. metal pillars), laser targets for the following scan registration phase, and photogrammetric targets placed on the ground and then used as GCPs for UAV image triangulation.

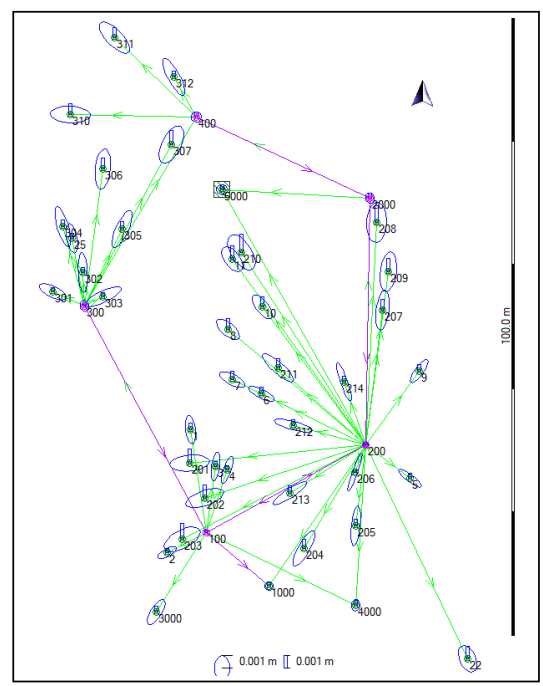

Fig. 4. Geodetic network and error ellipses.

In all, the network consists in 399 observations (distances, directions and zenith angles) and 155 unknowns; global redundancy is therefore 244 degrees of freedom.

It is important to notice that several points were measured from multiple stations and all tripods were fixed during the whole survey. Least Squares adjustment provided a submillimeter precision for stations and points with multiple intersections, whereas the remaining points have an average precision of about $\pm 1.5 \mathrm{~mm}$.

The laser scanning survey is made up of 19 scans acquired with a FARO FOCUS 3D (see Fig. 5). Although this work mainly focuses on the analysis of thermal data, the final aim of this project includes the modeling in a BIM of architectural remains around the church. Scan registration was performed by using checkerboard targets (measured with the total station) and registration spheres. Some spheres were also placed on the geodetic tripod with an adaptor that allows one to exchange the sphere with standard reflector prisms. Registration statistics shows an average precision of $\pm 3 \mathrm{~mm}$.

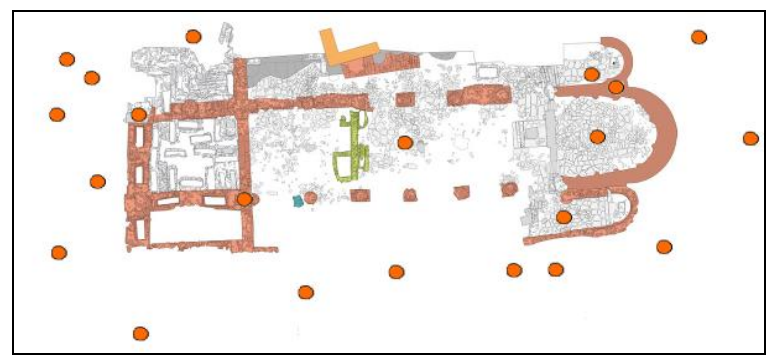

Fig. 5. Scan positions for the laser survey.

\subsection{UAV survey}

The photogrammetric survey of the site was carried out with the UAV platform AscTec Falcon 8. The system is equipped with an RGB camera Sony NEX-5N and a thermal camera FLIR TAU 640 (Fig. 6) photogrammetrically calibrated (Previtali et al., 2013).

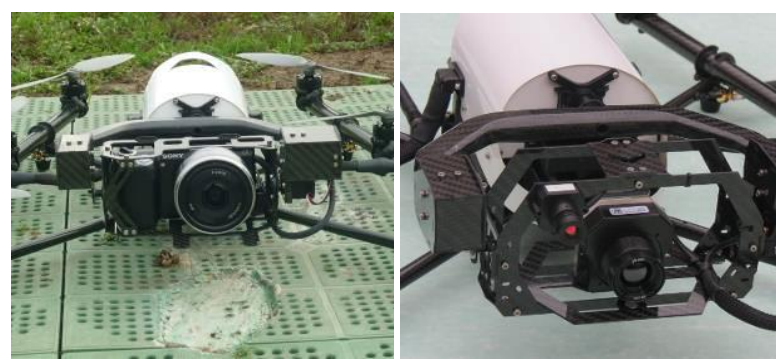

Fig. 6. Cameras (RGB and TIR) mounted on the Falcon that were used for this survey.

The Falcon 8 (70 $\mathrm{cm} \times 60 \mathrm{~cm}$, weight $2 \mathrm{~kg}$ ) is equipped with 8 motors and is able to fly up to 20 minutes with a single battery. The electronic equipment includes a GPS antenna and a system of accelerometers determining the system roll, pitch and yaw. The communication system allows the ground station to receive telemetry data and video signals from the onboard sensors.

Image acquisition for the site St. Eufemia was divided in different phases in order to optimize flight time (Fig. 7): a larger area corresponding to the remains of the church of St. Eufemia (Site A - about $40 \times 70 \mathrm{~m}^{2}$ ) and another one (about $25 \times 60 \mathrm{~m}^{2}$ ) that includes the remains of the baptistery (Site B). A consideration about flight permissions deserve to be mentioned. In Italy, licensing requirements for flying UAVs within the international directives have not been defined yet. The UVS-Info (Remotely Piloted Systems Information Source http://www.uvs-info.com/) classified drones (June 2011) with some parameters like the flight altitude, payload and flight duration (the Falcon8 can be classified as a micro UAV). Platforms with weight less than $150 \mathrm{~kg}$ must follow the directive of national authorities, as established by the EU directives. In Italy, they are controlled by the Ente Nazionale per il Controllo Aereo (ENAC). Nowadays, the activities carried out with UAVs are not regulated by ENAC directives: there is no specific regulation for flying UAVs or a distinction between requirements for commercial and research purposes. Only a preliminary draft of the first regulation was recently published by ENAC (2012), but this draft is not officially used at the moment. In this draft there is 
a distinction between sport and commercial purposes. The discussion about this point is not clear. It started two years ago because it seems too limitative not only for research purposes, but also for an open market that could be significantly improved in different fields. Experiments coordinated by ENAC concerning the first identification of risk scenarios, technical roles and assurances (including complex contexts such as urban areas) are in progress with an Italian company (Aermatica) whose results are expected to be published and usable for all the users on the market. Once a specific regulation has been defined, it will be easier for producers and users to make better use of it in order to fly in an open market.

On Isola Comacina, RGB image acquisition was carried out by using different heights above ground. The first flight has a height of about $30 \mathrm{~m}$ and provides a ground coverage of about $30 \times 45 \mathrm{~m}^{2}$. The second flight (height $50 \mathrm{~m}$ ) has the primary aim to strengthen network geometry. The planned overlap was about $80 \%$, while overlap between consecutive strips was $60 \%$. A total number of 50 images was taken for the first site, 42 for the second.

Before flying, 24 targets were materialized on the ground by using rigid black and white marks (Fig. 7) homogeneously distributed in the area. They were used as Ground Control Points (GCPs) and check points (CPs) to register the photogrammetric project and for accuracy evaluation. The 3D coordinates of these targets were measured with a pole equipped with a $360^{\circ}$ reflector prism.
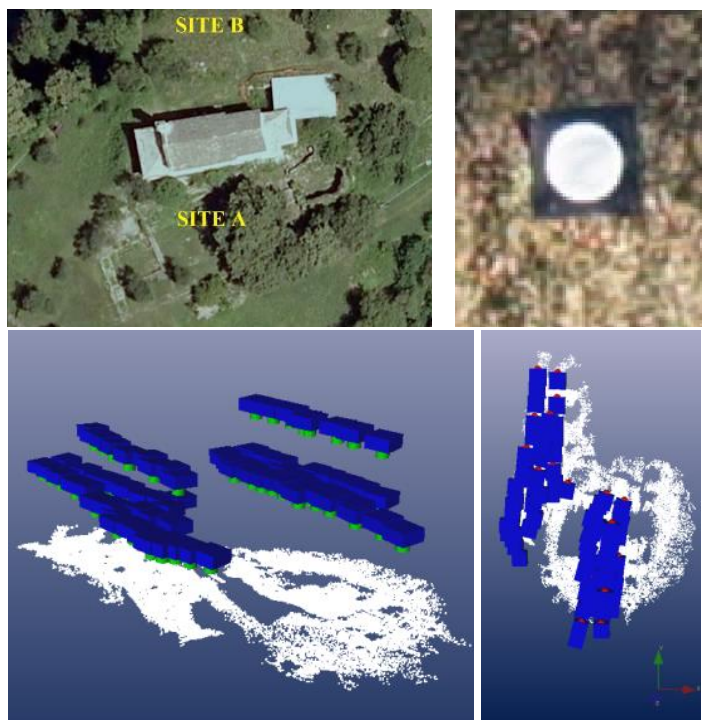

Fig. 7. Sites, a GCP and 3D visualization of orientation results (camera poses).

Automated triangulation of UAV images is today a topic of great interest (Barazzetti et al., 2010). According to Eisenbeiss (2009) "not all software packages could be used in all possible applications of UAV photogrammetry; quite often, only the combination of several packages enabled us to completely process the data set". This statement is verified by our findings.

In fact, in our work we integrated two commercial software: PhotoModeler 2012 for image orientation and Agisoft PhotoScan, for DEM and orthophoto generation.

The reader may ask why two distinct packages were employed: they offer the same functionalities (image orientation, DEM extraction, etc.). Initially, images were oriented with PhotoScan but results were not completely satisfactory. The software allows for fully automatic image orientation in an arbitrary reference system and scale. Once images are oriented GCPs can be manually measured and their coordinates in the local reference system assigned. In this way the photogrammetric block is referenced in the total station reference system.

On the other hand, the obtained RMS values of GCPs were $29.8 \mathrm{~mm}, 26.9 \mathrm{~cm}$ and $55.1 \mathrm{~mm}$ in the $\mathrm{X}, \mathrm{Y}$ and $\mathrm{Z}$ directions. These errors are also probably due to the limited overlap between both blocks (site A and B) and a residual network deformation. It should be mentioned that GCPs are not only useful to establish a reference system, but they can control network deformations. Image orientation was therefore repeated with PhotoModeler 2012 and its aerial triangulation routine termed SmartPoints. Image orientation was firstly performed with a free-network adjustment by using more than 128,000 tie points identified by SIFT. Then, some additional tie points were measured in the overlap area between the Sites A and B and finally the exterior orientation parameters were computed by using the GCPs, reorienting all the images. Here, bundle adjustment is intended as an orientation process where GCPs are included as pseudoobservations weighted according to geodetic network precision (not only a 7-parameter transformation). GCP image coordinates were measured in a semi-automated way by using the Least Squares Matching algorithm (Grün, 1985). The new LS adjustment gave a sigma-naught of 0.51 pixels and residuals on 12 check point coordinates (RMSE values) of $4.7 \mathrm{~mm}, 5.6 \mathrm{~mm}$, and $8.7 \mathrm{~mm}, \mathrm{X}-\mathrm{Y}-\mathrm{Z}$ respectively.

Starting from the estimated exterior orientation parameters a Digital Elevation Model (DEM) was generated. EO parameters were transferred to PhotoScan to run its multiview reconstruction algorithm aimed at obtaining high quality 3D models. The parameters for geometry generation were set by fixing a maximum number of 5 million faces. Once the 3D triangulated model was generated the DEM was obtained by setting a grid size of $3 \mathrm{~cm}$ (Fig. 8). Finally the orthophoto of the entire area was derived with a resolution of $9 \mathrm{~mm}$.
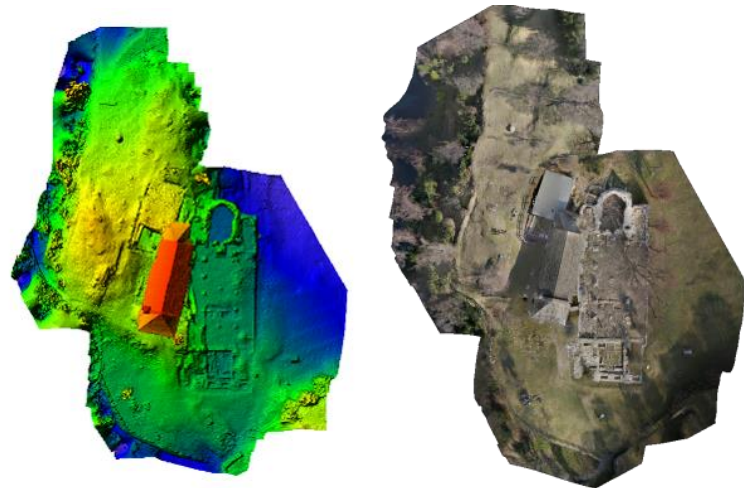

Fig. 8. DEM and RGB orthophoto.

\section{ANALYSIS, PROCESSING AND INSPECTION OF THERMAL IMAGES}

As mentioned, the study not only focuses on small details of the sites (or parts of these sites), but it includes wider geological and topographic aspects (Fig. 9). A part of the research is to study the use of thermal imagery. For example, 
this type of imagery can help to discover rock formations partially buried.

It is well-known that the inhabitants of the island needed to invade the topography of the island and cut out their houses in the slopes of the rock hard local stone called 'moltrasio'. Remnants of these activities can be found all over the island, as well as buried remains of the fortification system. Not the discovery of these specific locations or buried structures but the suggestion of the discovery and the way to discover these aspects through (thermal) survey is one of the scope of the research.

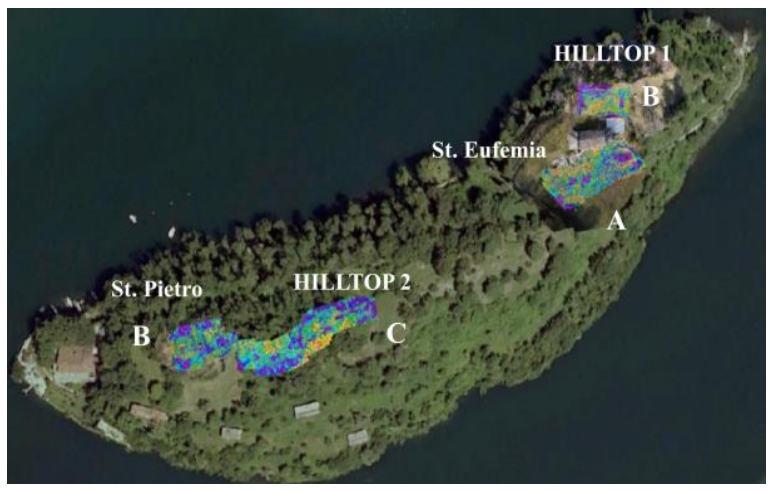

Fig. 9. Thermal orthophotos for the investigated sites.

In this work thermal images were turned into georeferenced products (orthorectification) in order to combine radiometry (temperature) and metric data. Different levels of thermal data processing (image orientation and thermal texture mapping) were employed.

The first level (say level 1) provides accurate thermal orthophotos by means of a combined bundle adjustment of RGB and thermal images. This procedure is feasible because the thermal camera was photogrammetrically calibrated beforehand (IO and additional parameters, see Previtali et al., 2013). Thermal images were then included in the RGB adjustment by using some RGB/thermal tie points manually measured, as proposed in Barazzetti et al. (2013). This combined orientation strategy has the main advantage to strengthen the network geometry and allows an estimation of orientation parameters much better than those obtainable with standard space resection techniques. In this adjustment the target coordinates (surveyed with a total station) were used as Ground Control Points (visible in both categories of images) in combination with some tie points extracted from both RGB and thermal images. Sigma-naught was about \pm 0.8 pixels and allowed to obtain a detailed thermal orthophoto for the church of St. Eufemia (see Fig. 10 for a global overview and a detail).

An alternative approach (level 2) was used for the sites St. Pietro and Hilltop 1. As the terrain is relatively flat, the resolution of thermal images is quite limited, and other external information was not available (e.g. 3D target coordinates measured by total station or GPS) a solution based on a 2D independent model adjustment was implemented by using a multi-image affine as geometric transformation. A color orthophoto was derived from a block of RGB images acquired with the Falcon 8. Then, georeferencing of thermal imagery was based on both artificial targets and natural points measured on the high resolution RGB orthophoto. Points were used to estimate transformation parameters from which a georeferenced thermal mosaic was generated (Fig. 11).
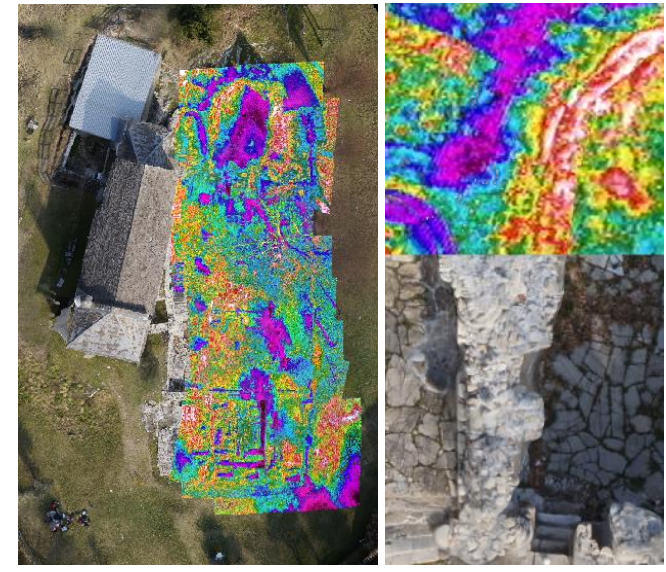

Fig. 10. Thermal and RGM orthophotos derived from rigorous UAV image triangulation ( $\mathrm{RGB}+$ thermal - level 1) for the site St. Eufemia.

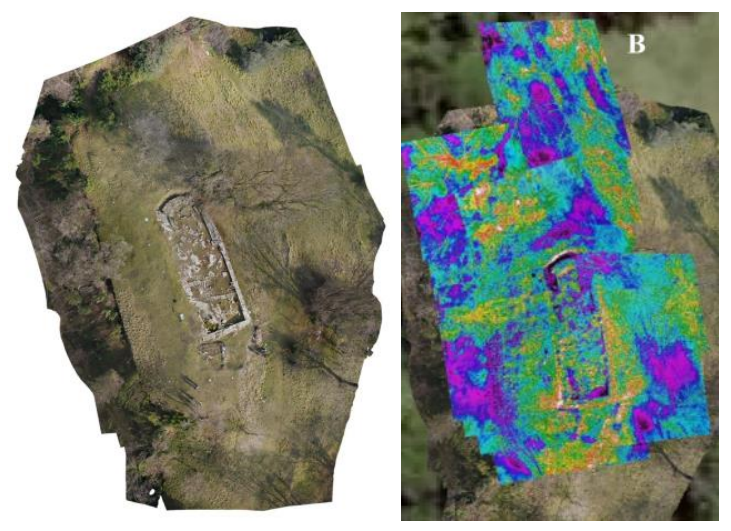

Fig. 11. RGB and thermal orthophoto for St. Pietro in Castello derived from an multi-image affine-based Least Squares adjustment (level 2).

The combined inspection of both thermal and RGB imags in a GIS allowed one to (re)discover buried traces. In particular, for the site of St. Pietro in Castello, the IR imagery helped to better outline a defensive or supportive wall running parallel with the longitudinal axis of the former church (Fig. 12 top).

On the site Hilltop 1, it was known that that several wall structures were uncovered during previous excavation campaigns, but they are not visible because of a new vegetated layer and are 'forgotten' (Fig. 13). The use of thermal images from UAVs could be a valid support to determine the location and layout of these structures.
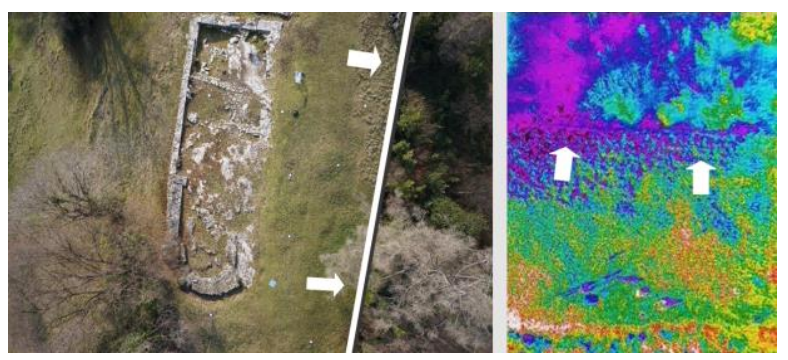

Fig. 12. Remains of a (supportive/defensive) wall for the site St. Pietro in Castello. 

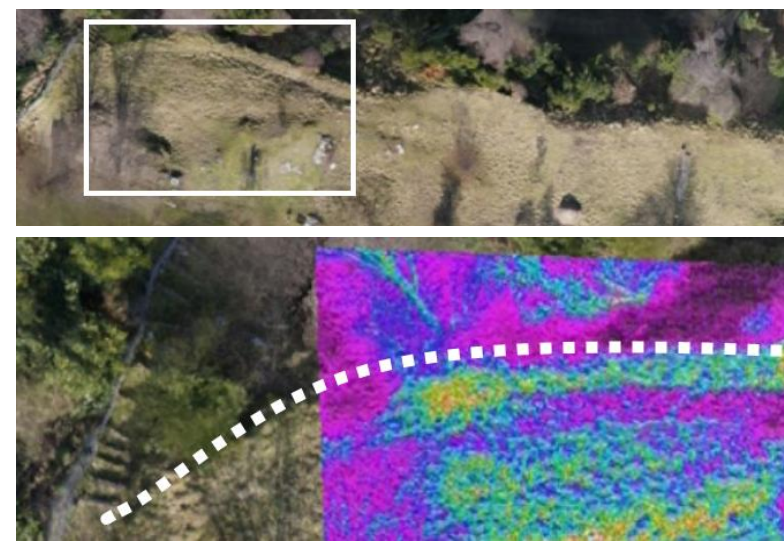

Fig. 13. Remains of a (supportive /defensive) wall for the site Hilltop 1.

Finally, the last level (level 3) is simply based on a rapid and approximate georeferencing based on the extraction of corresponding points directly on thermal images and the estimation of an affine transform for each image. Data processing is supported by the low quality GPS path to obtain georeferenced results. This methodology has some limitations but it was sufficient for the inspection of the site Hilltop 2, where only thermal data were acquired because of dense vegetation.

\section{CONCLUSION}

The work presented in this paper is only the first step towards a complex project including digital documentation and metric information for the whole archaeological site of Isola Comacina. In this kind of environmental situation it is important to use different surveying techniques in order to obtain an accurate and detailed documentation, starting from the single building up to the whole archeological site. In particular, the use of UAV platforms can be useful to generate standard RGB orthophotos. Then, a thermal camera allowed one to obtain thermal orthophotos of some parts of the island. Thanks to these additional UAV data, more research can be done towards the topographic situation and location of the whole island and its sites, the connection with the mainland (harbor areas) and of course the (re)location of (un)known sites still buried (the whole island used to be a vivid city).

The geodetic network was created not only to georeference laser and photogrammetric data (RGB and thermal), but also past documentations, investigations, geometrical and thematic surveys. In other words, it overcomes the lack of an unique reference system for all the archaeological buildings on the island, that is an obstacle for a project of valorization, conservation and maintenance of the whole site.

In this research the phase of interpretation and registration of thermal data can be intended as "the beginning", notwithstanding results are quite promising. Different methodologies (slow and rigorous or fast but approximate) were needed to overcome different practical limitations for thermal orthophoto production. Future work will require the comparison of these new observations with historical, thematic and other material data in order to validate the historical and stratigraphic interpretation.

\section{REFERENCES}

Barazzetti, L., Remondino, F., Scaioni, M., Brumana, R., 2010. Fully automatic UAV image-based sensor orientation. IAPRSS\&IS, ICWG I/V, June 15-18, Calgary, Canada.

Barazzetti, L., Erba, S., Previtali, M., Rosina, E., Scaioni, M. (2013). Mosaicking thermal images of buildings. Proc. of SPIE Videometrics, Range Imaging, and Applications XII, Vol. 8791A, Munich, Germany.

Brumana, R., Oreni, D., Alba, M., Barazzetti, L., Cuca, B., Scaioni, M., 2011. Panoramic UAV views for landscape heritage analysis integrated with historical map atlases. 23th Int. CIPA Symposium, 12-16 September, Prague, 8 pages.

Canziani, A., Della Torre, S., 2010. Le Case per artisti sull'Isola Comacina. Nodolibri, Como.

D’Amia, G., 2005. L'isola degli artisti: un laboratorio del moderno sul Lago di Como. Mimesis, Milano.

Eisenbeiss, H., 2009. UAV photogrammetry. Diss. ETH No. 18515, Institute of Geodesy and Photogrammetry, ETH Zurich, Switzerland, Mitteilungen Nr.105, p. 235.

Eisenbeiss, H., Sauerbier, M., 2011. Investigation of UAV systems and flight modes for photogrammetric applications. The Photogrammetric Record, 26(136), pp. 400-421.

ENAC, 2012, DRAFT1, Bozza del Regolamento Mezzi aerei a pilotaggio remoto, Protocollo del 27/12/2012 http://www.enac.gov.it/Home/

Gianoncelli, M., 1973. Note storiche su l'Isola Comacina, in: Archivio Storico Lombardo, Como.

Glennie, C., Brooks, B., Ericksen, T., Hauser, D., Hudnut, K., Foster, J., Avery, J., 2013. "Compact Multipurpose Mobile Laser Scanning System - Initial Tests and Results", Remote Sensing, 2072-4292.

Grün, A., 1985. Adaptive least square correlation - a powerful image matching technique. S. Afr. J. of. Photogrammetry, Remote Sensing and Cartography, 14(3), pp 175-187.

Jaakkola, A., Hyyppä, J., Kukko, A., Yu, X., Kaartinen, H., Lehtomäki, M., Lin, Y., 2010. A low-cost multi-sensoral mobile mapping system and its feasibility for tree Measurements. In: ISPRS Journal of Photogrammetry and Remote Sensing Vol. 85-6, pp. 514-522.

Previtali, M., Barazzetti, L., Brumana, R., Cuca, B., Oreni D., Roncoroni, F., Scaioni M. (2013). Automatic facade segmentation for thermal retrofit. International Archives of the Photogrammetry, Remote Sensing and Spatial Information Sciences, Volume XL5/W1, 25-26 February 2013, Trento, Italy, 8 pages.

Remondino, F., Barazzetti, L., Nex, F., Scaioni, M., Sarazzi, D., 2011. UAV photogrammetry for mapping and 3D modelling current status and future prospective. IAPRSS\&IS, Zurich, Switzerland, Vol. XXXVIII, Part 1, 25-31.

Rinaudo, F., Chiabrando, F., Lingua, A., Spanò, A., 2012. Archaeological site monitoring: UAV photogrammetry can be an answer. IAPRSS\&IS, Melbourne, Australia, Vol. XXXIX, Part B5, pp. 583-588.

Sauerbier, M., Eisenbeiss, H., 2010. UAV for the documentation of archaeological excavations. IAPRSS\&IS, Newcastle upon Tyne, UK, Vol. XXXVIII, Part 5, pp. 526-531.

Seitz, Ch., Altenbach, H., 2011. Project Archeye - the quadrocopter as the archaeologist's eye. IAPRSS\&IS, Zurich, Switzerland, Vol. XXXVIII, Part 1, pp. 297-302. 